\title{
Usage of Social Media Systems in Customer Service Strategies
}

\author{
Alexander Rossmann \\ Reutlingen University \\ Alexander.Rossmann @ \\ reutlingen-university.de
}

\author{
Tim Wilke \\ Reutlingen University \\ Tim.Wilke@ \\ reutlingen-university.de
}

\author{
Gerald Stei \\ Reutlingen University \\ Gerald.Stei@ \\ reutlingen-university.de
}

\begin{abstract}
This paper examines the efficacy of social media systems in customer complaint handling. The emergence of social media, as a useful complement and (possibly) a viable alternative to the traditional channels of service delivery, motivates this research. The theoretical framework, developed from literature on social media and complaint handling, is tested against data collected from two different channels (hotline and social media) of a German telecommunication services provider, in order to gain insights into channel efficacy in complaint handling. We contribute to the understanding of firm's technology usage for complaint handling in two ways: (a) by conceptualizing and evaluating complaint handling quality across traditional and social media channels and (b) by comparing the impact of complaint handling quality on key performance outcomes such as customer loyalty, positive word-of-mouth, and crosspurchase intentions across traditional and social media channels.
\end{abstract}

\section{Introduction}

Customer complaints are recurrent and complaint handling is an important indicator of a firm's customer centricity and overall service quality [1]. Barring a few studies that examined firm success rate and the cost involved in such decisions [2], the use of social media systems in customer complaint handling services remains largely unexplored. We examine whether firms are better off using social media as part of their channel strategy for handling customer complaints by comparing them with traditional channels.

Firms are adopting social media as part of their communication strategies [3]. This includes multiple decisions, e.g. usage of platforms like Facebook and Twitter, implementation of social media monitoring software, and internal processes. Therefore, social media is not just an additional channel. Moreover, the implementation of social media as a service and marketing strategy leads to a system of decisions, processes, and technologies. In a customer service context, social media helps firms to analyze customer online communication, identify service issues at an early stage, create satisfying service experiences, and provide customers with a direct and convenient way to share their sentiments by electronic word-of-mouth. Research evidence suggests that companies which complement their service strategy with social media systems are more successful [4, 5]. However, considerable costs are involved in the implementation of new communication systems [2], and channel expansion decisions have a long-term impact on a firm's performance [6]. In short, whether firms are better off using social media systems or not remains an open question.

Comparing the performance of social media against traditional channels, this study examines the concept of perceived complaint handling quality (PCHQ), conceptualized as the complainer's subjective assessment of the complaint handling service [7]. Therefore, we address three open questions of interest: (a) how should PCHQ be conceptualized across different channels?; (b) how strong are the effects of different facets of PCHQ on customer satisfaction and other key performance outcomes?; and (c) how effective are social media channels as compared to traditional channels for customer complaint handing?

To answer these research questions, we followed a three-step approach: (a) a literature review of complaint handling and service recovery research, (b) collecting supporting evidence from a survey of customers and marketing executives across traditional and social media channels, (c) an empirical comparison of the research model using customer-level data collected in an online survey.

Our findings illustrate that it is not always in the firm's best interest to use feature-rich channels such as social media. Though use of social media systems is expected to improve the quality of solutions and reduce customer effort, their marginal impact on satisfaction and subsequently on behavioral intentions is lower than traditional media. In sum, we contribute to the understanding of firm's channel strategy for complaint handling in two ways: (a) by evaluating complaint handling quality across different channels and (b) by comparing the impact of complaint handling quality on 
key performance outcomes such as customer loyalty, positive word-of-mouth, and cross-purchase intentions across traditional and social media channels.

\section{Complaint Handling}

Early studies of complaint management [8, 9] agreed that the customer's perception of fairness in complaint handling has three distinct dimensions, i.e. distributive, procedural, and interactional justice. This three-dimensional structure was theorized and tested in a meta-analytic framework proposed by Orsingher et al. [10]. Distributive justice refers to customer perception regarding the firm's effort to correct the observed problem [11]. Procedural justice refers to how the complainant perceives the procedure of decision making and conflict resolution undertaken by the firm. A procedurally fair complaint handling process is easy to access, provides customer control over its disposition, is flexible, and concludes in an appropriate and timely manner [12]. Interactional justice refers to the behavior of employees during the complaint handling process. It is associated with the employee's empathy, politeness, treatment, and related efforts to make up for the complaint $[12,13]$.

However, recent studies have questioned the distinctness of these three justice dimensions [14]. Several studies integrate the dimensions and treat them as a single construct, due to high correlation between the dimensions [15].

Given the conflicting findings around the dimensionality of PCHQ, we derive the initial conceptualization of PCHQ based on a review of the current literature that accumulated possible lines of evidence (or descriptive codes) in a spreadsheet. Thereafter, these codes were interpreted and synthesized to yield 15 distinct facets of PCHQ, which were iteratively segregated into five coherent dimensions. The three dimensions of perceived justice plus, a fourth dimension for the quality of the core service solution emerged.
The fifth dimension was an outcome of splitting the construct of distributive justice into two lower-level constructs - one due to the general evaluation of fairness during the complaint handling process, and another for the perception of the effort customers are willing to make in order to resolve a complaint.

We used these 15 facets in an exploratory survey of managers and consumers to ensure further robustness. Data was collected across the 15 facets of PCHQ from a three-part sample, comprising both customers and service providers across a multi-channel context of social media and traditional channels. The three different samples included a group of service agents plus two groups of consumers (one each from social media (Facebook and Twitter) and traditional service channels (hotline). The sample was drawn from a list of marketing executives and customers of a telecommunication service provider in Germany. The firm operates its own service community on Facebook, as well as a special complaint handling account on Twitter, as part of its corporate strategy for effectively dealing with service complaints. The customers of this provider also receive complaint handling services through traditional channels such as hotline, shops, and letters.

The presentation of the results of this exploratory evaluation phase goes beyond the available scope of this paper. However, Figure 1 shows the identified five subdimensions of PCHQ as (a) procedural justice, (b) interactional justice, (c) distributive justice, (d) customer effort, and (e) quality of service solutions. We integrate these facets of PCHQ and anchor them in expectation-disconfirmation theory with a view to modeling customer satisfaction as a mediator of the impact of PCHQ on three key performance outcomes (customer loyalty, word-of-mouth, and cross-purchase preferences). Additionally, the main effects are tested for a possible moderating role for the type of service channel (social media vs. hotline). 


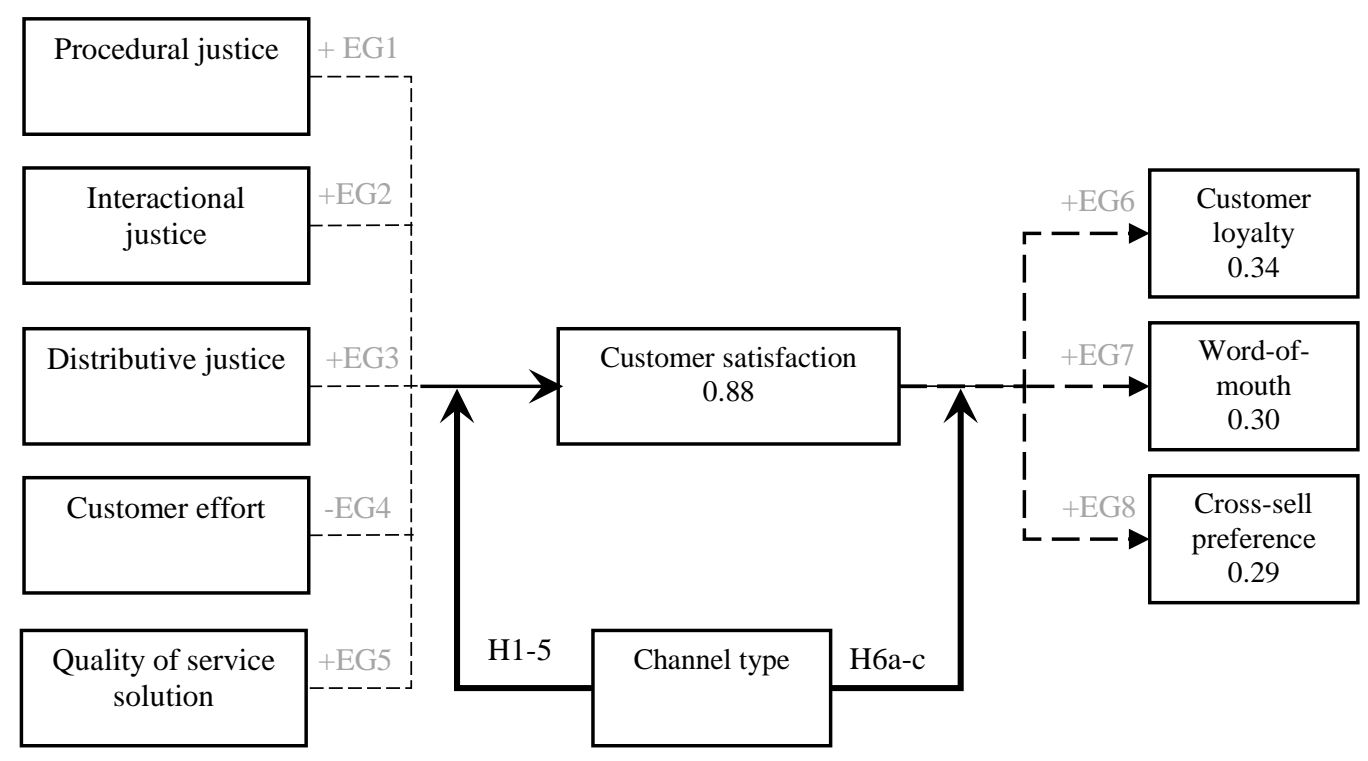

Figures indicate the respective $R^{2}$ values $\mathrm{EG}=$ Empirical generalization; $\mathrm{H}=$ Hypotheses

Figure 1. Conceptual Framework

\section{Conceptual Framework and Hypotheses}

As our focus is to understand PCHQ and how its dimensions vary in strength across the two types of channels, we hypothesize in detail those aspects that have not been tested in prior research and might not necessarily generalize along the two channels. As most of the main effects are expected to generalize across channel types even in the context of complaint handling, only a brief discussion is provided here, although such relationships are indicated as empirical generalizations.

\subsection{Customer Satisfaction: Its Variation across PCHQ Dimensions}

Social media channels are highly vivid due to multimedia features such as colors, pictures, sound, animations, graphics, and interactive components. Vividness, on one hand, causes an increase in perceived accessibility of information triggering perception of superior quality; on the other hand, it results in the formation of (higher) expectations, which, in turn, influences satisfaction [16, 17].

This apparent paradox provides an interesting context for comparing the effect of various facets of
PCHQ on overall customer satisfaction across social media and traditional channels. According to the expectancy-disconfirmation theory, customers compare a complaint handling service with their prior expectations. Therefore, we consider satisfaction in terms of its 'transaction-specific component', in contrast to the alternative view of an 'overall' assessment of the company and its services [14].

Procedural justice. Procedural justice refers to the degree to which an organizational procedure for registering and processing customer complaints exists and is consistent with complainants' needs [1]. It has been examined in terms of timing and speed and found to impact customer satisfaction $[1,7,12]$. Therefore procedural justice, viewed in terms of timeliness and as a process for solving a current problem, positively impacts customer satisfaction (EG1).

Does this main effect vary across channels? Social media channels are more egalitarian by nature and provide the customer with more control. Ubiquitousness and memory capacities of digital channels allow quick and customized procedures for complaint handling [17, 18]. Moreover, the flexibility in social media channels ensures superior procedural justice in complaint handling [19]. Complaint handling in social media is further enhanced by dynamically generated messages to customer comments, which 
improves the response time. The responsiveness increases the interactivity of the medium [20]. Therefore, in social media channels, procedural justice is more pronounced.

H1: The positive main effect of procedural justice on customer satisfaction is higher for social media channels than for traditional channels.

Interactional justice. Studies in service quality support a central role for interactional justice in service delivery [8]. Hence, interactional justice is an integral component of PCHQ. Scholars argue that the interactional behavior exhibited by employees towards complainants, which includes customer perceptions of employee politeness [9], employee empathy [12], and employee effort [7] during a recovery process, serves to augment customer satisfaction (EG2).

Social media allows for ease of partnering and engagement between firm and customer [21]. The company's actions, including the service delivery effort, are more transparent and visible in social media. According to parasocial interaction (PSI) theory [22], social media can offer an illusionary experience of engagement and reciprocal relationship with mediating personas. Thus, on one hand, the influence of PSI in social media communication makes the customers feel better about the way they are treated; on the other hand, due to the vividness property of social media, interactional justice is rendered more accessible. Therefore, we hypothesize a stronger effect of interactional justice on customer satisfaction in social media than the same effect in traditional channels.

H2: The positive effect of interactional justice on customer satisfaction is higher in social media channels than in traditional channels.

Distributive justice. Distributive justice, rooted in equity theory, refers to whether or not the ratio of an individual's output (benefits) to input (financial and nonfinancial efforts) is balanced with that of relevant others [11]. If the differences between input and output are unduly against or in favor of the individual, then feelings of disappointment or anger in the former case and feelings of guilt or regret in the latter case might ensue. Customers who perceive the organizational response to a complaint as relatively fairly distributed, tend to be more satisfied [14, 23] and this relation is indicated as EG3 in Figure 1.

The Internet is generally considered as a costeffective fun-space. In fact, online shopping sites and some of the associated features such as online shopping carts are used by consumers simply as an 'entertainment or as a shopping research and organizational tool' [24]. Social media allows costeffective and personalized procedures for customers and can now change the intensity and meaning of messages in multiple ways [16, 17]. Social media are informative and educational because of the multitude of socialization agents, not to mention the role played by peer customers, who also enable resolution of doubts and queries. The higher interactivity increases the possibility of affective and convenient socialization [25]. Even when the firm puts in the same level of effort, social media brings greater interactional benefits to the customer. Therefore, we hypothesize a stronger effect of distributive justice on satisfaction for complaint handling via social media.

H3: The positive effect of distributive justice on customer satisfaction is higher in social media channels than in traditional channels.

Customer effort. Fifty-nine percent of customers report that they expended moderate to high effort in resolving a complaint [26]. Customer effort comprises cognitive, emotional, physical, and time elements. A low expense of customer effort creates vibes of high quality. Firms employ different methods to reduce customer effort - Nedbank (getting the same person to respond to a request every time), Osram Sylvania (avoidance of negative language), Cisco (creating a complaint channel for each complaint), Travelocity (improving its help section), and Ameriprise Financial (capturing 'No' in responses) [26]. Expenditure of higher effort causes lower overall satisfaction, and this relationship is retested in the context of complaint handling as empirical generalization, EG4.

Customer expectations from social media have amplified in recent years [22]. Customers share the impression that services in social media channels are convenient and reduce service costs - both monetary and nonmonetary. Also, social media facilitate easy generation of content through multitasking and are expected to reduce customer effort [27]. If customers come with a lower expected effort than their usual experience and effort in traditional channels, when that expectation is disconfirmed, their dissatisfaction is raised as a result. Hence, we hypothesize the following relationship:

H4: The negative effect of the amount of effort customers need to invest in customer satisfaction is higher in social media channels than in traditional channels.

Quality of service solutions. A large-scale study of contact center and self-service interactions determined that what customers really want (but rarely get) is a satisfactory solution to their service issue [26]. The quality of the core service solution to a complaint has a positive effect on customer satisfaction. Thus, we hypothesize that customers appreciate receiving a 
viable and tangible solution to their current problem [12]. Therefore, improving the quality of service solutions can amplify customer satisfaction with the service organization (EG5).

Complaint handling through social media is timely and interactive; however, this may not necessarily translate into superior core quality of solutions. This is because the quality of solutions to customer queries may depend on other factors such as employee behavior, expertise and other resources of the firm [28, 29]. Moreover, customers are aware of features provided by social media such as interactivity and multitasking, and expect better solutions to their complaints than from traditional media. We therefore hypothesize that:

H5: The positive effect of the perceived quality of delivered service solutions on customer satisfaction is lower in social media channels than in traditional channels.

\subsection{Outcome Intentions}

Scholars argue that the behavioral intentions of a customer are predominantly driven by overall satisfaction with a service [30]. We integrate transaction-specific customer satisfaction as a mediating construct between complaint handling quality and key behavioral intentions - the two most important ones being loyalty and word-of-mouth [13]. Loyalty refers to a customer's intention to continue to do business with an organization [14]. Positive wordof-mouth is the likelihood of spreading positive information about an organization [30, 31]. Jeng [32] found that corporate reputation and satisfaction raise cross-buying intentions by decreasing information costs and enhancing trust and affective commitment. Similarly, studies by Bolton and Lemon [33] and Mittal and Kamakura [34] show a positive effect of satisfaction on further usage levels and repurchase behavior and cross-purchase preferences. Therefore, we posit a positive relationship between customer satisfaction and the intentional outcomes of loyalty, word-of-mouth, and customer preferences across channels (EG6-8).

Furthermore, it is important to consider if different customer service channels influence the effect of customer satisfaction on the three performance outcome variables. Theoretical evidence for a differential impact of customer satisfaction in a hotline and social media service channel is expected, given the different communication settings within the channels. Social media are informal in nature and provide a high level of interconnectedness [17], facilitating the sharing of content within product and service groups such as brand communities [35]. They are also an important enabler of customer socialization and communication, because they provide an easy and convenient way for people to communicate over the internet [36]. Customers have increased control over the content and can manage its intensity and meaning in multiple ways [21]. Therefore, the difference between hotline and social media is expected to moderate the impact of customer satisfaction on outcomes such as loyalty, word-of-mouth communication, and cross-selling. Therefore:

H6a-c: The positive effect of customer satisfaction on loyalty, word-of-mouth communication, and crossselling will be moderated by the channel type, and will be higher for social media than traditional channels.

\section{Method}

The hypotheses were tested using data supplied by the customer service department of a German telecommunications provider. We used two different samples in this study, one from a traditional hotline channel (sample A) and another from social media (sample B). The data was collected immediately after a service experience. In sample A, customers were invited by email to take part in the service survey immediately after a hotline contact. In sample B, customers received a comparable invitation by email, by direct message (Twitter), or by direct mail (Facebook).

The questionnaire was based on guidelines formulated by Churchill Jr [37] and Gerbing and Anderson [38]. Whenever possible, existing scale items were used after necessary rewording. Multi-item, seven-point, Likert-type scale items were used to measure the constructs. The questionnaire was pilot tested with 10 marketing and service executives of the telecommunication provider. After suitably improving the questionnaire, a pretest involving 186 customers was conducted to develop measures which were valid and reliable [39]. A final sample size of 440 was formed by 220 customers from hotline and 220 customers from social media. The conceptual model was tested in two stages: (a) structural equation modeling (SEM) was deemed suitable for testing the measurement model and estimating the main effects and, (b) a multi-sample analysis was performed to compare the hypothesized effects across the two channels [40].

The unidimensionality and convergent validity of the constructs were examined by confirmatory factor analysis (CFA) performed using LISREL. Common method bias was tested with three tests. First, Harman's one factor method [41] revealed that the first 
factor of all items in the measurement model did not account for the bulk of the variance, indicating that common method bias is not a problem. Secondly, we loaded all the items on to a common factor and conducted CFA. The results were then compared with the results of CFA in the measurement model [42]. Finally, we used the common latent factor method [41] and none of the factor loadings of the items to their respective constructs show a significant drop, implying that common method bias is not a problem.

\section{Results}

After the measurement model was deemed acceptable, we estimated a structural path model to test the hypotheses depicted in Figure 1. The fit indexes for the cross-channel sample $(n=440)\left(\chi^{2}(300)=512.09\right.$,
$\mathrm{CFI}=.991 ; \mathrm{NFI}=.981 ; \mathrm{NNFI}=.990 ; \mathrm{RMSEA}=.040)$ suggest that the model acceptably fits the data [43]. A chi-square difference test reveals that a model with direct effects (direct paths from the antecedent variables to the three target variables) does not have significantly better fit indexes than our full mediation model, suggesting that our model provides a better explanation of the data [44].

The correlations, means, and standard deviations of the nine focal constructs are displayed in Table 1. All constructs show sufficient correlation in the hypothesized direction. Accordingly, the paths of the conceptual model, estimated $\beta$-factors of main effects, corresponding $t$-values of the causal model, and squared multiple correlations (total variance explained) of the four target constructs are displayed in Table 2.

Table 1. Correlation matrix, means, and standard deviations

\begin{tabular}{|c|c|c|c|c|c|c|c|c|c|c|c|}
\hline Construct & $M$ & SD & 1 & 2 & 3 & 4 & 5 & 6 & 7 & 8 & 9 \\
\hline 1 Procedural Justice & 4.04 & 1.46 & 1 & & & & & & & & \\
\hline 2 Interactional Justice & 4.06 & 1.57 & .72 & 1 & & & & & & & \\
\hline 3 Distributive Justice & 4.22 & 1.39 & .51 & .44 & 1 & & & & & & \\
\hline 4 Customer Effort & 3.31 & 1.49 & -.01 & -.20 & .07 & 1 & & & & & \\
\hline 5 Quality of Service Solutions & 3.92 & 1.61 & .70 & .71 & .63 & -.16 & 1 & & & & \\
\hline 6 Customer Satisfaction & 4.12 & 1.55 & .81 & .81 & .58 & -.29 & .85 & 1 & & & \\
\hline 7 Customer Loyalty & 3.7 & 1.28 & .59 & .59 & .42 & -.22 & .62 & .60 & 1 & & \\
\hline 8 Word-of-mouth & 4.43 & 1.38 & .46 & .47 & .33 & -.17 & .49 & .55 & .53 & 1 & \\
\hline 9 Cross-sell Preferences & 4.25 & 1.48 & .50 & .50 & .36 & -.18 & .52 & .55 & .25 & .66 & 1 \\
\hline
\end{tabular}

$M=$ Mean, on a scale of 1 to $7 ; \mathrm{SD}=$ Standard deviation; $N=440$

For absolute value of $r>0.05, p<0.05$, for absolute value of $r>0.15, p<0.01$

For absolute value of $r<-0.05, p<0.05$, for absolute value of $r<-.15, p<0.01$

Table 2. Test of general relationships

\begin{tabular}{lccc}
\hline \multicolumn{1}{c}{ Construct relationship } & Main effect & $\begin{array}{c}\text { Squared } \\
\text { multiple } \\
\text { correlations }\end{array}$ \\
\cline { 2 - 4 } EG1: Procedural justice $\rightarrow$ Customer satisfaction & $\boldsymbol{\beta}$-value & .34 & 8.37 \\
EG2: Interactional justice $\rightarrow$ Customer satisfaction & .25 & 6.39 \\
EG3: Distributive justice $\rightarrow$ Customer satisfaction & .09 & 2.84 \\
EG4: Customer effort $\rightarrow$ Customer satisfaction & -.20 & -8.00 & .88 \\
EG5: Quality of service solutions $\rightarrow$ Customer satisfaction & .35 & 8.00 & .34 \\
EG6: Customer satisfaction $\rightarrow$ Customer loyalty & .73 & 13.05 & .30 \\
EG7: Customer satisfaction $\rightarrow$ Word-of-mouth & .58 & 11.01 & .29 \\
EG8: Customer satisfaction $\rightarrow$ Cross-sell preferences & .62 & 11.85 & \\
\hline$N=440$
\end{tabular}

$N=440$ 
All eight generalizations received strong and significant support in the cross-channel sample. The quality of the service solution $(\beta=.35, p<.001)$ and procedural justice $(\beta=.34, p<.001)$ have the strongest influence on customer satisfaction in the total sample. In contrast, distributive justice impacts only with $\beta=.09$ $(p<.001)$ on customer satisfaction. Moreover, squared multiple correlations show that the model explains a sufficient amount of the total variance of the four targets constructs. Overall, $88 \%$ of the variance of customer satisfaction is explained by our model. Approximately, one-third of the variance of customer loyalty, word-of-mouth, and cross-sell preferences is explained solely by customer satisfaction.

Furthermore, we used multi-sample analysis method to assess the differences between the hotline and social media samples $[45,46]$ in a single LISREL model [47]. The test of invariance between the two measurement models in both samples provides significant support for sufficient pre-conditions for multi-sample analysis [43]. Hence, we tested the general model fit, differences in $\beta$-values, and $t$-values. Results are displayed in Table 3. Fit indexes for multisample analysis $\left(\chi^{2}(618)=993.37, \mathrm{CFI}=.984 ; \mathrm{NFI}=\right.$ .964 ; NNFI $=.982$; RMSEA $=.053$ ) suggests that the multi-sample model acceptably fits the data. First of all, the general fit of the conceptual model in both samples supports the applicability of our model for assessing the influence of PCHQ in different channels. All formulated moderation of hypotheses $\mathrm{H} 1-\mathrm{H} 5$ are supported. However, out of the outcome hypothesis, only the word-of-mouth relationship is significantly moderated, whereas there is no significant or only small difference between the two channels on the satisfaction-loyalty or satisfaction-repurchase intentions relationships.

Table 3. Multi-sample analysis of moderation effects

\begin{tabular}{llllccc}
\hline & \multirow{2}{*}{ Construct relationship } & \multicolumn{3}{c}{ Hotline } & \multicolumn{3}{c}{ Social Media } \\
& & & $\boldsymbol{\beta}$ & $\boldsymbol{t}$-value & $\boldsymbol{\beta}$ & $\boldsymbol{t}$-value \\
\hline H1: Procedural justice & $\rightarrow$ & Customer satisfaction & .23 & 3.23 & .29 & 3.33 \\
H2: Interactional justice & $\rightarrow$ & Customer satisfaction & .20 & 1.70 & .22 & 5.09 \\
H3: Distributive justice & $\rightarrow$ & Customer satisfaction & .11 & 2.21 & .24 & 2.93 \\
H4: Customer effort & $\rightarrow$ & Customer satisfaction & -.17 & -3.01 & -.33 & -7.85 \\
H5: Quality of service solutions & $\rightarrow$ & Customer satisfaction & .48 & 4.49 & .18 & 3.04 \\
H6a: Customer satisfaction & $\rightarrow$ & Customer loyalty & .68 & 8.47 & .77 & 9.90 \\
H6b: Customer satisfaction & $\rightarrow$ & Word-of-mouth & .40 & 5.21 & .79 & 10.67 \\
H6c: Customer satisfaction & $\rightarrow$ & Cross-sell preferences & .64 & 8.74 & .64 & 8.60 \\
\hline
\end{tabular}




\section{Discussion}

Social media systems have emerged as a vital supplement to traditional channels in a firm's multichannel strategy. The use of multiple channels extends beyond value creation and dissemination stages to customer complaint handling processes. This study contributes to the understanding of the quality perception of complaint handling and its consequences, and compares these relationships across social media and traditional channels.

We extend the three-dimensional fairness-centric conceptual model of Orsingher et al. [10], and enrich the extant understanding about the multidimensional construct of PCHQ by elaborating its five dimensions and explaining the effect and variation of each dimension across social media and traditional channels. Moreover, we specify the scope of distributive justice, and enhance the understanding of PCHQ beyond the general evaluation of fairness by the addition of two new constructs of customer effort and the perceived quality of the solution. Each dimension is made more tractable for further research as well as practice, by spelling out the constituent items or facets of the five dimensions. Furthermore, we find that while procedural justice and interactional justice are nearly equally efficacious across the two channels, distributive justice, customer effort, and quality of service are, in contrast, significantly differ in their salience across the hotline and social media channels. Such improved understanding of PCHQ will provide fresh impetus to research around these constructs. The five dimensions of PCHQ were also tested for their effect on customer satisfaction (EG1EG5), and a subsequent impact on three key marketing outcomes (EG6-EG8). The general model fit of the full-sample and the two sub-samples, along with substantial explanation in the four endogenous constructs provides evidence for the robustness of the theorized model.

Does social media channel perform better than a traditional channel for certain elements of complaint handling? We show that the quality of service solutions and procedural justice have the strongest impact on customer satisfaction across both channels. Therefore, these two constructs might be viewed as the most important dimensions of PCHQ. Interactional justice also plays an important role in customer satisfaction $(\beta=.25)$, whereas the effect of distributive justice is generally low $(\beta=.09)$. Customer effort negatively affects customer satisfaction $(\beta=-.20)$, indicating that firms need to reduce the share of customer effort in the process of complaint handling. The main effect of satisfaction on word-of-mouth, loyalty, and intention to crosspurchase (EG6-8) supports prior findings [30, 31].

A multigroup SEM using samples from a traditional hotline channel and a social media channel indicates the comparative efficacy of the two types of channels. This leads to some important differences in effect size and carries implications for specific channel strategies. Social media makes the role of distributive justice $\left(\beta_{\text {SOCIAL }}=.24\right)$ and customer effort $\left(\beta_{\text {SOCIAL }}=-.33\right)$ more salient, indicating that firms need to manage these two factors closely in pursuit of a social media channel strategy. On the other hand, the role of core service quality is of great importance in the traditional channel strategy $\left(\beta_{\text {нот }}=.48\right)$. The results also indicate that a satisfied customer in a social media channel is a superior asset for a firm than a customer served through traditional channels, because the former is more inclined to generate word-of-mouth communication $\left(\beta_{\text {SOCIAL }}=79\right)$. This may signify the use of social media channels as an effective strategy for firms eyeing customer referral value, as in the case of firms such as Asus, which was able to reach a formidable number-three position in the US tablet market in a record time, simply by relying on strong reviews and positive word-ofmouth.

While scholarly research is divided on the importance of social media as an alternative channel of distribution, marketing executives believe that social media channels are superior in performance in terms of complaint handling and implementing multiple channels. Our findings indicate that any increase in customer effort with respect to complaint handling in social media might substantially reduce satisfaction as compared to traditional media. Additionally, our results show the points of benefits where digital channels can be used in tandem with traditional channels and also in what situations firms should not opt for feature-rich channels such as social media. For example, the impact of all perceived justice dimensions on satisfaction is higher in social media than in hotline; however, customers using services from traditional channels value core service quality more than anything else - this is so because, while social media do not affect the core service, they raise the customer's expectation from the channel, resulting in higher possibilities of negative disconfirmation of customer expectation. Moreover, social media act also as vehicles of communication media, while the traditional hotline is more of a solution channel.

We conclude on a note of caution about the generalizability of findings across 'different' social media channels - this is because the social media are constantly evolving and gaining in internal diversity. 
Therefore, further research might expand the scope of this research by observing other social media platforms in a complaint handling context. Similarly, hotline is only a limited representation of the diverse set of traditional channels, and might be only a distal representation of a wider cluster of traditional channels. Hence, additional research is required to test the framework for generalizability across a broader set of service channels. Additionally, the antecedents for PCHQ and the impact on key performance outcomes might differ across different service issues. A customer's channel choice and perceptions regarding complaint handling quality might change due to the exact nature of the customer problem. Therefore, future research would benefit from comparing online channels with traditional channels in a general and wider service context and from corroborating our findings.

\section{References}

[1] Homburg, C., and Fürst, A., "How Organizational Complaint Handling Drives Customer Loyalty: An Analysis of the Mechanistic and the Organic Approach", Journal of Marketing, 69 (3), 2005, pp. 95-114.

[2] Homburg, C., Vollmayr, J., and Hahn, A., "Firm Value Creation Through Major Channel Expansions: Evidence from an Event Study in the United States, Germany, and China", Journal of Marketing, 78 (3), 2014, pp. 38-61.

[3] Avery, J., Steenburgh, T.J., Deighton, J., and Caravella, M., "Adding Bricks to Clicks: Predicting the Patterns of Cross-Channel Elasticities over Time", Journal of Marketing, 76 (3), 2012, pp. 96-111.

[4] Sousa, R., and Voss, C.A., "Service Quality in Multichannel Services Employing Virtual Channels", Journal of Service Research, 8 (4), 2006, pp. 356-371.

[5] Weinberg, B.D., and Berger, P.D., "Connected customer lifetime value: The impact of social media", Journal of Direct, Data and Digital Marketing Practice, 12 (4), 2011, pp. 328-344.

[6] Bone, S.A., Fombelle, P.W., Ray, K.R., and Lemon, K.N., "How Customer Participation in B2B Peer-toPeer Problem-Solving Communities Influences the Need for Traditional Customer Service", Journal of Service Research, 18 (1), 2015, pp. 23-38.

[7] Smith, A.K., Bolton, R.N., and Wagner, J., "A Model of Customer Satisfaction with Service Encounters Involving Failure and Recovery", Journal of Marketing Research, 36 (3), 1999, pp. 356-372.

[8] Blodgett, J.G., Hill, D.J., and Tax, S.S., "The effects of distributive, procedural, and interactional justice on postcomplaint behavior", Journal of Retailing, 73 (2), 1997, pp. 185-210.
[9] Goodwin, C. and Ross, I., "Salient Dimensions of Perceived Fairness in Resolution of Service Complaints", Journal of Consumer Satisfaction, Dissatisfaction and Complaining Behavior, 2 (14), 1989, pp. 87-92.

[10] Orsingher, C., Valentini, S., and de Angelis, M., "A meta-analysis of satisfaction with complaint handling in services", Journal of the Academy of Marketing Science, 38 (2), 2009, pp. 169-186.

[11] Mayser, S., and von Wangenheim, F., "Perceived Fairness of Differential Customer Treatment: Consumers' Understanding of Distributive Justice Really Matters", Journal of Service Research, 16 (1), 2013, pp. 99-113.

[12] Tax, S.S., Brown, S.W., and Chandrashekaran, M., "Customer Evaluations of Service Complaint Experiences: Implications for Relationship Marketing”, Journal of Marketing, 62 (2), 1998, pp. 60-76.

[13] Van Vaerenbergh, Y., Larivière, B., and Vermeir, I., "The Impact of Process Recovery Communication on Customer Satisfaction, Repurchase Intentions, and Word-of-Mouth Intentions", Journal of Service Research, 15 (3), 2012, pp. 262-279.

[14] Gelbrich, K., and Roschk, H., "A Meta-Analysis of Organizational Complaint Handling and Customer Responses", Journal of Service Research, 14 (1), 2011, pp. 24-43.

[15] Homburg, C., and Giering, A., "Personal characteristics as moderators of the relationship between customer satisfaction and loyalty - An empirical analysis", Psychology \& Marketing, 18 (1), 2001, pp. 43-66.

[16] de Vries, L., Gensler, S., and Leeflang, P.S.H., "Popularity of Brand Posts on Brand Fan Pages: An Investigation of the Effects of Social Media Marketing”, Journal of Interactive Marketing, 26 (2), 2012, pp. 83-91.

[17] Hennig-Thurau, T., Hofacker, C.F., and Bloching, B., "Marketing the Pinball Way: Understanding How Social Media Change the Generation of Value for Consumers and Companies", Journal of Interactive Marketing, 27 (4), 2013, pp. 237-241.

[18] Hennig-Thurau, T., Malthouse, E.C., Friege, C., et al., "The Impact of New Media on Customer Relationships", Journal of Service Research, 13 (3), 2010, pp. 311-330.

[19] Malthouse, E.C., Haenlein, M., Skiera, B., Wege, E., and Zhang, M., "Managing Customer Relationships in the Social Media Era: Introducing the Social CRM House", Journal of Interactive Marketing, 27 (4), 2013, pp. 270-280.

[20] Song, J.H., and Zinkhan, G.M., "Determinants of Perceived Web Site Interactivity", Journal of Marketing, 72 (2), 2008, pp. 99-113. 
[21] Peters, K., Chen, Y., Kaplan, A.M., Ognibeni, B., and Pauwels, K., "Social Media Metrics - A Framework and Guidelines for Managing Social Media", Journal of Interactive Marketing, 27 (4), 2013, pp. 281-298.

[22] Labrecque, L.I., "Fostering Consumer-Brand Relationships in Social Media Environments: The Role of Parasocial Interaction", Journal of Interactive Marketing, 28 (2), 2014, pp. 134-148.

[23] Patterson, P.G., Cowley, E., and Prasongsukarn, K., "Service Failure Recovery: The Moderating Impact of Individual-Level Cultural Value Orientation on Perceptions of Justice", International Journal of Research in Marketing, 23 (3), 2006, pp. 263-277.

[24] Kukar-Kinney, M., and Close, A.G., "The Determinants of Consumers' Online Shopping Cart Abandonment", Journal of the Academy of Marketing Science, 38 (2), 2009, pp. 240-250.

[25] Muratore, I., "Teenagers, Blogs and Socialization: A Case Study of Young French Bloggers", Young Consumers: Insight and Ideas for Responsible Marketers, 9 (2), 2008, pp. 131-142.

[26] Dixon, M., Freeman, K., and Toman, N., "Stop Trying to Delight Your Customers", Harvard Business Review, 88 (7-8), 2010, pp. 1-16.

[27] Gensler, S., Völckner, F., Liu-Thompkins, Y., and Wiertz, C., "Managing Brands in the Social Media Environment", Journal of Interactive Marketing, 27 (4), 2013, pp. 242-256.

[28] Brady, M.K., and Cronin Jr., J.J., "Some New Thoughts on Conceptualizing Perceived Service Quality: A Hierarchical Approach", Journal of Marketing, 65 (3), 2001, pp. 34-49.

[29] Ranjan, K.R., Sugathan, P., and Rossmann, A., “A Narrative Review and Meta-Analysis of Service Interaction Quality: New Research Directions and Implications", Journal of Services Marketing, 29 (1), 2015, pp. 3-14.

[30] Davidow, M., "Organizational Responses to Customer Complaints: What Works and What Doesn't", Journal of Service Research, 5 (3), 2003, pp. 225-250.

[31] Davidow, M., "The Bottom Line Impact of Organizational Responses to Customer Complaints", Journal of Hospitality \& Tourism Research, 24 (4), 2000, pp. 473-490.

[32] Jeng, S.-P., "The Effect of Corporate Reputations on Customer Perceptions and Cross-Buying Intentions", The Service Industries Journal, 31 (6), 2011, pp. 851862.

[33] Bolton, R.N., and Lemon, K.N., "A Dynamic Model of Customers' Usage of Services: Usage as an Antecedent and Consequence of Satisfaction", Journal of Marketing Research, 36 (2), 1999, pp. 171-186.

[34] Mittal, V., and Kamakura, W.A., "Satisfaction, Repurchase Intent, and Repurchase Behavior: Investigating the Moderating Effect of Customer
Characteristics", Journal of Marketing Research, 38 (1), 2001, pp. 131-142.

[35] Kuksov, D., Shachar, R., and Wang, K., "Advertising and Consumers' Communications", Marketing Science, 32 (2), 2013, pp. 294-309.

[36] Köhler, C.F., Rohm, A.J., de Ruyter, K., and Wetzels, M., "Return on Interactivity: The Impact of Online Agents on Newcomer Adjustment", Journal of Marketing, 75 (2), 2011, pp. 93-108.

[37] Churchil, G.A., "A Paradigm for Developing Better Measures of Marketing Constructs", Journal of Marketing Research, 16 (1), 1979, pp. 64-73.

[38] Gerbing, D.W., and Anderson, J.C., "An Updated Paradigm for Scale Development Incorporating Unidimensionality and Its Assessment", Journal of Marketing Research, 25 (2), 1988, pp. 186-192.

[39] Homburg, C., and Fürst, A., "See No Evil, Hear No Evil, Speak No Evil: A Study of Defensive Organizational Behavior towards Customer Complaints", Journal of the Academy of Marketing Science, 35 (4), 2007, pp. 523-536.

[40] Cole, D.A., Maxwell, S.E., Arvey, R.D., and Salas, E., "Multivariate group comparisons of variable systems: MANOVA and structural equation modeling", Psychological Bulletin, 114 (1), 1993, pp. 174-184.

[41] Podsakoff, P.M., MacKenzie, S.B., Lee, J.-Y., and Podsakoff, N.P., "Common Method Biases in Behavioral Research: A Critical Review of the Literature and Recommended Remedies", Journal of Applied Psychology, 88 (5), 2003, pp. 879-903.

[42] Grace, D., and Weaven, S., "An Empirical Analysis of Franchisee Value-in-Use, Investment Risk and Relational Satisfaction", Journal of Retailing, Special Issue: Franchising and Retailing, 87 (3), 2011, pp. 366-380.

[43] Byrne, B.M., "Structural Equation Modeling with LISREL, PRELIS, and SIMPLIS: Basic Concepts, Applications, and Programming", Psychology Press, Mahwah, 2013.

[44] Bagozzi, R.P., and Yi, Y., "On the Evaluation of Structural Equation Models", Journal of the Academy of Marketing Science, 16 (1), 1988, pp. 74-94.

[45] Ping Jr., R.A., “A Parsimonious Estimating Technique for Interaction and Quadratic Latent Variables", Journal of Marketing Research, 32 (3), 1995, pp. 336347.

[46] Stone, E.F., and Hollenbeck, J.R., "Clarifying Some Controversial Issues Surrounding Statistical Procedures for Detecting Moderator Variables Empirical Evidence and Related Matters", Journal of Applied Psychology, 74 (1), 1989, pp. 3-10.

[47] Jöreskog, K.G., and Sörbom, D., "LISREL 8: User's Reference Guide", Scientific Software International, 1996. 